\title{
A STUDY OF THE EMOTIONS.
}

BY W. H. B. STODDART, M.D., M.R.C.P.

(1) The Physical Basis of the Emotions.

IN the following paper I shall endeavour to establish these two propositions :- -

(1) That an emotion is a sensation-complex, its component sensations being entirely derived from a complex, usually involuntary, motor response to a percept or idea of some situation or incident.

(2) That the motor paths subserving the function of this involuntary response are those of the primitive nervous system, viz.:- the cortico-rubral system of fibres and the rubro-spinal tract.

There are some psychologists who would take exception to the word "entirely" in my first proposition, and who would say that organic sensations are merely superadded to a tone of feeling which is in some way attached to the idea of the situation. Professor Titchener, for example, writes in his "Outlines of Psychology": "It is essential, then, for the formation of an emotion, (1) that a train of ideas shall be interrupted by a vivid feeling; (2) that this feeling shall mirror a situation or incident in the outside world; and (3) that the feeling shall be enriched ${ }^{1}$ by organic sensations, set up in the course of bodily adjustment to the incident."

Professor Titchener makes no attempt to explain the origin of this supposed initial feeling; but, as there are several psychologists who still share his view, it becomes necessary, in the first place, to re-state the case for the opposite side, which regards an emotion as a complex of organic sensations. 
The most elementary type of emotion is the feeling of pleasantness or unpleasantness which attaches to simple sensations. Introspection of these tones of feeling is very difficult, for reasons which will be understood later. For the present, it may be noted that attention to a tone of feeling necessitates inattention to the sensation by which it is aroused. Observations have been accordingly made on the physical concomitants of affection, and it has been shown by means of-

(1) The plethysmograph-That a positive tone of feeling (pleasantness) is accompanied by an increase of bodily volume (dilatation of arterioles), and a negative tone (unpleasantness) by a decrease.

(2) The sphygmograph-That a positive tone of feeling is accompanied by an increase of pulse frequency, a negative tone by a decrease.

(3) The pneumograph-That a positive tone is accompanied by an increase, a negative tone by a decrease of the depth of respiration.

(4) The dynamometer-That a positive tone is accompanied by an increase of muscular power, a negative tone by a decrease.

(5) The automatograph (a scientific form of planchette) -That a positive tone is accompanied by abduction of the arm, and a negative tone by adduction.

A tone of pleasantness or unpleasantness never arises without some or all of these physical accompaniments. They are the results of a general tendency on the part of the organism to reach out to that which is pleasant and useful and to withdraw from that which is unpleasant and harmful. There is little doubt that future research will discover many more movements associated with tones of feeling.

We are constantly using this phrase "tone of feeling" in discussing the nature of affection; and by retrospection, which differs but slightly from, and is in many cases the same thing as, introspection, we find that the phrase is well founded. The affective tone of pleasure or pain is a feeling or sensation superadded to the sensation which gives rise to it ; and it becomes our duty to look round and see if we can 
discover any stimuli which may be regarded as the cause of this superadded sensation.

The experimental results obtained by means of the plethysmograph, pneumograph, automatograph, \&c., supply the evidence we seek. We find that in affective states, stimuli to muscular and circulatory sensations occur in all parts of the body; and it is to be inferred that these give rise to the superadded sensations which constitute the feelings of pleasantness and unpleasantness.

From the above considerations, therefore, we learn that feelings of pleasantness and unpleasantness are due to muscular and circulatory sensations which result from complicated movements evidently reflex in nature.

Now, the tone of feeling which attaches to a percept or idea is much more complex in nature than that which attaches to a simple sensation, and it has correspondingly a very much larger number of varieties. Inasmuch as the emotional tone differs with almost every percept, idea and concept of things, people, incidents and situations, which may occur, a satisfactory classification of the emotions is practically an impossibility. The feeling of attraction towards people and things may take the form of interest, familiarity, intimacy, reverence, or love. Repulsion may take the form of dislike, disgust, antipathy, contempt, repugnance, disdain, hatred, and perhaps anger. Ideas of welfare may be associated with feelings of satisfaction, gratitude, contentment, joy, hope, or anticipation; ideas of harm with feelings of sorrow, grief, dissatisfaction, resignation, despair, fright, or horror. And if the ideas are of the welfare or injury of others, we may have feelings of gratification, gladness, envy, jealousy, regret, care, or sympathy. To all these add the emotions of misery, effort, decision, defiance, pride, shame, mirth, and the emotional tones which characterise mental operations, such as recognition, comparison, discrimination, judgment and reasoning; and the list remains yet incomplete, because our language cannot take account of the numerous intermediate and mixed shades of feeling which may attach to any one of the above-named emotions. 
It has been pointed out by Professor James that an emotion consists of a number of sensations, and that these sensations are derived from the activities of certain muscles (voluntary and involuntary), and glands (sudorific, lacrymal, intestinal, \&c.). The activities of involuntary muscles give rise to certain circulatory changes, such as increased or diminished frequency of the pulse, as well as to local flushings and pallors. And the more we investigate the matter, the more we become convinced that these sensations are the very essence of emotion. Let the reader conjure up some emotion, and note the various sensations he experiences therewith; then let him divest the emotional feeling of all these bodily sensations, and he will find that there is no part of the emotional feeling left. These various activities which give rise to the emotions are also responsible for the expression which indicates to others the nature of the particular emotion which is experienced.

According to this view, it is not the emotion which gives rise to the expression, but the expression which gives rise to the emotion. The question of the truth of this assertion has been appropriately referred to numerous actors: they have been asked whether they actually feel the various emotions they portray upon the stage. The best actors appear to be unanimous in the verdict that they actually feel the emotion they portray, especially when they are acting an emotional part well; and this is the reason why I have included the word " usually" in my first proposition. The experiences of the audience are in this connection no less interesting than those of the actor. When a member of the audience feels that he is being too much overcome by the sadness of the situation on the stage, he extends his trunk, assumes a smile, takes a deep breath, and surreptitiously wipes away the starting tear; by this means he dispels the emotion. And how often is an ill-timed merriment suppressed by assuming the expression, for example, of attention!

In this connection we now see why we are unable to attend to an emotion or affective tone. The particular combination of movements which constitutes the physical 
basis of attention disarranges the particular combination which constitutes the physical basis of other tones of feeling.

In the emotions accompanying pleasant ideas there is an increase of muscular tone and power with a tendency to extension of the trunk and abduction of the arms, an increase of pulse frequency with general dilatation of the arterioles, and an increase of the frequency and depth of respiration. In the emotions accompanying unpleasant ideas the reverse bodily conditions obtain. This much we have learned from the study of affection. But, in addition to these physical signs, there are others in the various emotions, each complex giving rise to that expression which is characteristic of the particular emotion. In anger, there is contraction of the corrugatores superciliorum, fixation of the gaze, dilatation of the nostrils, tightening of the lips, grinding of the teeth, clenching of the fists, extension of the trunk, and "flushing of the face. In disdain there is contraction of the levator labii superioris alæque nasi. In suspicion there is rapid lateral oscillation of the eyes. In dissent there is lateral nodding of the head, in assent there is antero-posterior nodding. If any of these expressions be well assumed, the corresponding emotion is experienced.

It has been shown by Darwin and others that all these apparently purposeless movements are in reality survivals of movements which have served some useful purpose in the past history of the race or of the individual. In anger, for example, the grinding 'of the teeth and clenching of the fists are survivals of similar movements performed upon portions of an enemy's flesh; the mouth being obstructed by such a portion of flesh, dilation of the nostrils becomes a necessity for breathing purposes. The gaze is fixed upon the enemy, and the contraction of the corrugators is necessary to protect the eyes from the sun during combat.

The contraction of the levator labii superioris alæque nasi in disdain is the uncovering of the canine tooth preparatory to biting the object of disdain. The oscillation of the eyes during suspicion is the search for anticipated danger. The lateral nodding of the head in dissent is a survival of the movement of refusing the proffered breast during infancy, and the movement of assent is that of accepting the breast. 
The general conclusion is, then, that an emotion is derived $e$ motu, out of motion, that it is a feeling compounded of sensations arising as a result of complex instinctive movements which are, as a rule, reflexly aroused by the situation in which the individual is placed.

In attempting to establish my second proposition, I leave out of consideration those emotions which are aroused by assuming the corresponding expression. This action is voluntary, and therefore has its physical basis in the motor area.

There is evidence to show that the thalamic region plays the most important rôle in the development of an emotion reflexly aroused. If a patient has a lesion of one optic thalamus, say the right, and you tell him a joke, he smiles on the same (right) side of the face only; the smile does not occur on the left side. That this paralysis is not due to a lesion of the cortex or pyramidal tract is shown by the fact that the two sides of the face act equally when he assumes a smile. If, on the other hand, the patient has a lesion of the right Rolandic area, he smiles equally on the two sides in response to a joke; but an assumed smile occurs on the right side only, volitional action being paralysed on the left side.

The observation of movements of expression occurring in the limbs is a more difficult matter in paralysed patients; the physician has to rely upon an opportunity of observing the hand when the patient yawns. In paralysis of the hand, due to some unilateral cortical lesion, the patient is unable to open the opposite hand voluntarily, but if he yawns, the hand opens slightly. If, however, a patient has a lesion in the region of one optic thalamus, he can open the opposite hand voluntarily, but it does not involuntarily open when he yawns. The conclusion to be drawn from these observations is that the tracts subserving the motor element of emotion cross to the opposite side of the cord.

Now, the only bundle which crosses from the mesencephalon to the opposite side of the cord is the rubro-spinal bundle of Monakow-that bundle which, as Held and 
Probst, and subsequently Buzzard and Collier, have shown, arises on the ventral side of the red nucleus, decussates in Forel's crossway with the corresponding bundle of the opposite side, and is traceable in the region of the lateral tracts as far as the sacral region of the spinal cord. It connects the opposite nucleus ruber with the ventral horn of the cord.

I therefore submit that Monakow's bundle subserves the function of the motor element of emotion. The only other tract which here deserves consideration is the thalamospinal tract of Buzzard and Collier. This is an uncrossed tract taking its origin deep in the thalamus and traceable as far as the lowest cervical region. My data are not sufficient to include or exclude this tract from the function of emotional reaction.

I now have to consider the cortical portion of the system of motor neurons subserving the function of emotion. For this function a system of fibres is required to connect the cortex with the nucleus ruber, and such a system has been described by M. and Mmc. Dejerine. The fibres take their origin in all parts of the cortex, but especially in the parietal lobe. They reach the thalamus just above the radiations of the internal geniculate body, enter into the constitution of the fillet, and reach the red nucleus at its antero-superoexternal part. These fibres are to be regarded as the upper segment of the emotional motor system. Their intimate anatomical relationship with the thalamus easily accounts for the fact that that structure has hitherto been regarded as the physical basis of movements of expression.

There is no evidence for or against the view that the cortico-thalamic and thalamo-spinal fibres may play a subsidiary rôle as part of the physical basis of movements of expression.

It is of considerable interest that the cortico-rubro-spinal motor system is at least the main representative of the primitive motor tract, the tract by which in the lower vertebrates all motor impulses are transmitted. It has been demonstrated by Münzner and Wiener, Boyce and Warrington, Edinger and others, that the pyramidal system of 
fibres does not exist in birds or in any of the lower vertebrates. In these animals the motor tract consists of cortico-thalamic and thalamo-spinal neurons only, the spinal fibres occupying the same relative position as the direct and crossed pyramidal system of mammals. In this connection it will also be remembered that in man the pyramidal tract is not myelinised until about the eighteenth month. Professor James has indicated the close relationship subsisting between emotions and instincts. Both are involuntary motor responses to sensations, percepts and ideas; and the only difference between them is that instincts bring the organism into more practical relation with the object of the idea, percept or sensation. Now, the lives of birds and lower vertebrates, and the life of the human infant until it is about eighteen months old, are practically little more than a mass of instinctive and emotional reactions; and it is not surprising to find that such reactions are, among the higher vertebrates, still dependent upon the functioning of the pristine nervous system.

The neural process which takes place when an emotion occurs is then as follows:-

Starting from the stage at which a sensation is registered in one of the projection areas, or a percept or idea formed in one of the association areas of the cortex, an impulse is transmitted to the red nucleus by way of the cortico-rubral fibres, thence to the large motor cells of the lowest level by way of Monakow's rubro-spinal (and presumably rubro-bulbar) fibres of the pristine motor system, and thence to the muscles of expression. Contraction of these muscles upon their spindles effects the transmission of muscle-sensations to the cortex by way of the ordinary sensory paths; and it is the particular combination of these sensations among themselves and with vaso-motor sensations which determines the given affective or emotional tone.

(2) The Pa'hology of 'rhe Emotions.

In this section I do not propose to deal with persistent states of depression or exaltation, but to consider morbid 
modifications of the emotional reaction to percepts or ideas of situations and incidents in the outside world. In the insane such emotional reaction may be excessive or deficient, the cause of this excess or defect differing in the various states with which we have to deal.

In those conditions dependent upon progressive deterioration of the nervous system, such as general paralysis, alcoholic insanity and, perhaps, epileptic insanity, the emotional reaction is excessive; hemiplegics, too, are very emotional; the most unimpressive word or gesture often suffices to induce an attack of weeping or laughter. The same may be said of imbecility, a condition in which the nervous system is ill-developed, and of states of maniacal excitement. Again, paranoiacs and patients suffering from hallucinations are usually liable to outbursts of anger and other forms of emotion. We have also to consider those patients who suffer from morbid fears.

Deficient emotional reaction, on the other hand, characterises confusional and stuporose states, senility and all forms of secondary dementia, myxœdema, and cretinism.

\section{(a) Excess of Emotional Reaction.}

The doctrine is now well established that dissolution of the nervous system takes place in reverse order to its evolution; and it has been demonstrated that the last motor tract to develop in the history of the vertebrate nervous system is the pyramidal tract. It is in accordance with this doctrine that the first motor tract to suffer in such progressive degenerations of the nervous system as general paralysis, alcoholic insanity and epileptic insanity, is the pyramidal tract; and the consequence is that in these diseases, and also in hemiplegia, motor impulses tend more and more to be transmitted by way of more primitive motor tracts viâ the thalamus.

Now, these are the very tracts which normally subserve the function of the emotional reaction; and so it happens that patients suffering from the above diseases react emotionally to unimpressive stimuli : their main outlet is by way of emotion-arousing tracts. 
I do not know whether the pyramidal tracts are especially ill-developed in imbeciles; but it is extremely probable that they are, for the patient is unable to walk properly in many cases. The nervous system as a whole is ill-developed, and it is to be supposed that the pyramidal tracts, which are normally myelinised late, are disproportionately affected. 'This being so, the above principle also applies to the excessive emotional reaction of imbeciles.

In states of maniacal excitement, the excessive tendency to emotional reaction is dependent upon a different set of conditions. I have elsewhere shown reason for the belief that mania is a state in which the neurons contain some irritating body or bodies; the neurons are consequently in a permanent state of excitability.

The result of this constant state of tension of the neurons in maniacal states is that minimal stimuli provoke nervous discharge and, in the case of motor neurons, induce contraction of muscles.

The application of this principle to the emotionality of maniacal patients is as follows :-A perceptual or ideational process occurs in one of the association-areas of the cortex ; all the neurons in functional communication with this area, especially the cortico-rubral neurons, are discharged: in other words, discharge takes place into the emotional regions of the nervous system.

Dr. Wolseley Lewis has drawn my attention to the fact that insane epileptics, while free in the movement of their large proximal joints, are stiff and cramped in the smaller ones. He also observes that the epileptic shakes hands from the shoulder. In these particulars, the epileptic resembles the maniac; and, from the principles which I laid down in my paper "On Motor Symptoms of Mania and Melancholia" (Lancet, March 5th, 1904), it is to be concluded that the neurons of epileptics, as well as those of maniacs, contain some irritating body within their substance. The motor neurons of epileptics are therefore in the same "touch-off" condition as those of maniacs, and this.affords us another explanation of the excessive tendency of epileptics to emotional reaction. Of course, it may be that the 
patients to whom Dr. Lewis refers are cases of epileptic mania.

The emotional outbursts of paranoiacs and of patients suffering from hallucinations may be looked upon as being due to excessive perception, in contrast to those forms of diminution of emotional reaction which are due to "imperception" (vide infra). The laughing or weeping of a patient who has just experienced an illusion or hallucination takes place because the patient has perceived something which is not there; he has suffered from excess of perception.

Similarly, paranoiacs suffer from an excess of perception ; their association of ideas is excessive, and they see hidden meanings in the most trivial incidents. A passer-by in the street blows his nose, and the paranoiac perceives the handkerchief as the cloak of a sneer or smile; the result is the emotional reaction we call anger.

Morbid fears are due to an abnormal tendency of the pristine nervous system to react to some particular percept. This tendency must, as a rule, be regarded as congenital, since it develops in people who are normally lacking in selfconfidence. The tendency is, however, sometimes acquired; some illness leaves the patient devoid of self-confidence, or some unusual incident may initiate this morbid tendency.

\section{(b) Deficiency of the Emotional Reaction.}

If you tell a person a good joke, there are three possible causes for his not laughing at it: (1) He does not hear it, (2) he does not "see" it, and (3) he is preoccupied. These are the three causes of diminution of emotional reaction in the insane.

In confused and stuporose states the patient suffers from anæsthesia of characteristic distribution. In such cases perception is deficient because sensations are not satisfactorily served up to the ideational centres; and emotional reaction is deficient for the same reason that a deaf man does not laugh when you tell him a joke. It is also to be observed that in these patients there is a further reason for the loss of emotional feeling in that the muscular sense is defective, so 
that the patient would not experience an emotional feeling even if a slight motor reaction should occur.

Emotional defect may be due to partial or complete imperception. In its typical form, imperception is a condition in which the patient is unable to recognise persons, objects and things; and it depends upon organic disease of the ideational areas. It also occurs to a greater or less extent in cases of secondary dementia, senility, myxœdema, and cretinism. In all these conditions there is corresponding deficiency of emotional reaction.

In some cases of this kind, emotional reaction occurs; but its character is inappropriate to the occasion. For example, it frequently happens that an advanced dement laughs on being told that some relative, once dear to him, is dead.

Absence or deficiency of emotional reaction also occurs in severe cases of melancholia. Professor Ribot mentions in his "Psychologie des Sentiments" some cases of melancholia in which there was complete absence of emotional reaction; but the name "anhedonia" which he bas given this symptom and the descriptions of his cases indicate that he has not quite fully grasped its significance. Cases of severe melancholia suffer from an absence, not only of pleasurable, but also of painful, emotional reactions. Such patients experience no pleasure when they think of their home, wife and family; as a rule they tell us that they have lost all affection for their friends; and when it becomes our painful duty to inform a melancholiac of the death of his nearest and dearest relative, he commonly remarks, "I don't seem to feel it."

The cause of this lack of emotional reaction is not far to seek. I have frequently pointed out that the greater part of the muscular system of melancholiacs is rigidly fixed owing to partial paralysis of cortical neurons, and Dr. Craig's observations that the blood-pressure of melancholiacs is raised indicates some fixation of the involuntary arterial muscle-fibres. It is on account of this motor and vaso-motor fixation that the motor and vaso-motor changes essential to emotional reaction cannot take place. 
Katatoniac stupor is also characterised by muscular rigidity. This rigidity differs from that of melancholia in that it affects the whole of the muscular system uniformly; whereas the rigidity of melancholia mainly affects the musculature of the spinal column and of the large proximal joints. Dr. Craig tells me that the blood-pressure is also raised in katatoniac stupor. The practical point is this, that in katatoniac stupor there is motor and vaso-motor fixation as in melancholia; and it is on account of this fixation that there is complete absence of emotional reaction in this condition.

Professor Kraepelin considers that there is an absence of emotional reaction in other forms of dementia precox. I have been unable to convince myself that this is the case, and, on the other hand, I am unable to discover any reason why there should be any lack of emotional response in most cases of simple dementia precox, hebephrenia or dementia paranoides.

The conclusions arrived at in this section may be summarised as follows: Excess or defect of emotional reaction may be dependent upon excess or defect of sensation, or upon excess or defect of perception. Excess of emotional reaction may also depend upon an abnormal tendency of motor impulses to be transmitted vi $\hat{a}$ the pristine emotionarousing motor tracts of the nervous system; and defect of emotional reaction may furtber be due to fixation of emotionarousing musculature. 